\title{
Analysis of the industrial solid wastes from the boat building sector in Marche region (Italy): parametrical and chemical-physical characterisation
}

\author{
M. Carchesio, F. Tatàno, G. Tosi, C. H. Trivellone, \\ E. Businaro \& F. Mangani \\ DiSBeF - Department of Base Sciences and Fundamentals, \\ Section of Bio-Mathematics, Environmental Modelling and Engineering, \\ Faculty of Sciences and Technologies, \\ University of Urbino "Carlo Bo", Italy
}

\begin{abstract}
This paper deals with a qualitative and quantitative analysis of the particular industrial solid waste generated from the renowned manufacturing sector of motor and sailing pleasure crafts in Marche Region (Central Italy, Adriatic Sea side). Three case-study boat-builder companies, located in the Marche regional district and selected for their representative production in glass-fibre or carbon fibre reinforced composite materials, were examined. Specific waste production coefficient values per employee were derived on a four-year temporal range (2006-2009) and also two original waste production coefficients (per boat-area unit and per boat-weight unit) were proposed. Furthermore, a chemical-physical characterisation was carried out for two representative composite waste typologies of the boat manufacturing sector, namely a carbon-fibre reinforced plastic residue and a glass-fibre reinforced plastic residue.
\end{abstract}

Keywords: boat building, characterisation, industrial waste, production.

\section{Introduction}

In accordance with the European waste framework legislation (Directive 2008/98/EC [1]) as implemented in Italy with the Legislative Decree 152/2006 [2], an integrated and sustainable waste management strategy should be defined 
with the following hierarchy: (1) prevention and/or reduction of waste quantity and harmfulness; (2) re-use; (3) recycling; (4) other recovery, e.g., energy recovery; and (5) final disposal as the last resort. Within a comprehensive perspective not limited exclusively to municipal solid waste, this hierarchical management approach should also be considered for different industrial waste typologies of manufacturing origin, which are included in the official and consolidated classification of the European Waste List ([3], as amended). Referring specifically to the industrial district of the Marche Region (Central Italy, Adriatic Sea side), the boat building sector certainly represents a significant productive area of the renowned manufacturing sector in Italy of motor and sailing pleasure-crafts.

To delineate a suitable and reliable integrated management plan for boat manufacturing wastes at a given territorial scale, as for example, within the mentioned Marche regional district, a primary feasibility step deals with the quantitative and qualitative analysis of the generated waste fluxes including the characterisation of the significant properties for representative waste types. In this perspective, the paper describes the analysis of the industrial solid wastes from the boat building sector in Marche Region carried out as the first phase of the "GeRISNaM" research project (being "GeRISNaM" the Italian acronym of the project title "Integrated and Sustainable Waste Management in the Boat Building Sector of Marche Region"). The investigation was focused on three case-study boat-builder companies located in the Marche regional district and selected for their representative production of glass-fibre or carbon-fibre reinforced composite materials. Specifically, case-study company " 1 " is specialised in the building of glass-fibre motorboats; case-study company " 2 " is specialised in the building of carbon-fibre sailing-boats; and case-study company " 3 " is specialised in the manufacturing of glass-fibre components. The annual total waste amounts over a four-year monitoring period (2006-2009) were derived for each case-study boat-builder company, as well as for the entire Marche regional district. On the basis of the available data, the parametrical characterisation of the waste fluxes was typically carried out by calculating the specific waste production coefficient per employee. Moreover, the parametrical characterisation was extended with the original proposal of specific waste production coefficients per boat-area unit and per boat-weight unit, which are expected to provide a more appropriate linkage of the waste generation with the manufactured product. Finally, the characterisation of some chemical-physical properties of two representative glass-fibre and carbon-fibre residual materials was performed.

\section{Materials and methods}

\subsection{Data collection}

The analysis of waste fluxes was based on three typologies of data: (1) qualitative and quantitative data describing the wastes produced in the boat building sector either in the whole Marche regional district or by the three case- 
study boat builder companies; (2) number of employees exclusively assigned to the boat manufacturing (i.e., without considering the administrative staff employed in the same sector) either in the entire Marche regional district or in the three case-study boat builder companies; and (3) some technical data of the boat models realised by the case-study boat builder companies. All these data collected refer to the four-year monitoring period 2006-2009.

The values of the regional waste amounts per each six-digit "CER" code (being "CER" the equivalent acronym in Italian language of the European Waste Catalogue in accordance with the consolidated European List of Waste [3]) were extracted from the data-base of the Italian "MUD, Compulsory Waste Declarations" organised by the Marche Regional Environmental Protection Agency (ARPA Marche). In particular, the "MUD" data were selected through the setting up of specific filter-queries, in function of precise territorial extensions (i.e., entire Marche Region, provinces of Marche Region, and towns of Marche Region) and the appropriate categories for the boat building sector according to the "ISTAT, Italian Statistical Institute" categorisation of the economic activities (namely: for the period before the 2008 year, the specific category "DM 35.12, construction and repairing of sportive and pleasure boats"; and for the period since $1^{\text {st }}$ January 2008, the new codified categories " $\mathrm{C} 30.12$, construction of sportive and pleasure boats" and "C $\mathrm{C} 3.15$, repairing and maintenance of sportive and pleasure boats"). Referring to the case-study company " 1 ", the related qualitative and quantitative waste flux evaluation in the four-year period 2006-2009 was based on the information gathered from the annual loading/unloading registers, i.e., the official registers where the waste producers have to note down all the movements for each "CER" waste category. The loading operation is when the waste is produced; the unloading operation is when the waste is disposed, i.e., when it is collected by specialised firms for final management and disposal. Taking into account that sometimes loading and unloading values can be different from each other, it was preferred to consider their arithmetic mean. For the case-study company " 2 ", only unloading operation values were available and thus considered. Similarly to the case-study company " 1 ", for the case-study company " 3 " the waste flux evaluation was carried out with data from loading/unloading registers for the 2006 year, while the "MUD" declarations were directly elaborated for the other three years (2007-2009).

In the technical-scientific literature, the waste generation is frequently characterised per defined time frame and per generating characteristic unit [4], thus permitting a parametrical characterisation in terms of "specific waste production coefficients" or alternately definable "unit generation rates". For commercial and industrial wastes, the unit generation rates are frequently determined per number of employees [5] due to the common availability of employment data [6]. Therefore, the knowledge of the number of workers for the boat building sector of the Marche regional district was of fundamental importance. In this context, data-bases of local authorities as the Pesaro-Urbino Chamber of Commerce, the Pesaro-Urbino Social Security, the Ancona Social Security, the Macerata Social Security, and the Ascoli Piceno Social Security 
were essential sources of reliable data. Similarly, for the three case-study companies the employee numbers were supplied by the companies themselves.

Indeed, the unit generation rate based on the number of employees is not always the best parametrical tool for the industrial waste flux characterisation despite its wide use. The updating of the employment statistics is, in fact, not constant and not regular and it is quite difficult to pick out the number of employees exclusively involved in the specific productive cycle. More appropriately, the unit generation rate should reflect the main factor or characteristic determining the waste generation [4]. Thus, in place of the employee's number, other factors could be applied as the reference parameter, notably: the number of productive units, the number of final commercial products, and the service units consumed in the productive cycle (as water, and electrical energy) [6]. Referring to the particular context of the boat building sector in this paper, some original parameters were identified as strictly connected with the technical and/or geometrical characteristics of the final products, i.e., sailing-boats or motor-boats. Precisely, the characteristic "length overall", "length waterline", and "draught" values (necessary to the calculation of the hull area) and the weights of the singular boats were provided by the casestudy company " 1 " and company " 2 " to this purpose.

Finally, with the aim of mapping the territorial diffusion and localisation of the boat building sector in Marche Region, also the number of the productive sites active in each singular town was considered. These last data were made available from the Chamber of Commerce of Pesaro-Urbino.

\subsection{Definition and calculation of specific waste production coefficients}

In this study, the specific waste production coefficients were determined for each year of the considered temporal range (2006-2009) as the ratio between the annual waste amount (total or diversified per two-digit "CER" code) and the overall value of the assumed reference parameter in the same year.

At first, a traditional "Waste Production Coefficient per Employee (WPCpE)" was derived as $t_{\text {waste }} \mathrm{e}^{-1} \mathrm{y}^{-1}$ (with " $\mathrm{t}$ ", " $\mathrm{e}$ ", and " $\mathrm{y}$ " referring to tonnes, employee, and year, respectively). Then, given the availability of technical data regarding the motor-boats of case-study company " 1 " and the sailing-boats of case-study company " 2 ", a new specific waste production coefficient was derived in relation to a possible geometrical characterisation of the boats, i.e., the definable "Waste Production Coefficient per boat-Area unit (WPCpA)". To this purpose and for the specific industrial sector analysed, the geometric surface of the hull was considered. Namely, the sum of the areas of bottom, board, side, transom and deck was taken into account for the motor-boats (Figure 1a) of case-study company " 1 " and for the sailing-boats (Figure 1b) of case-study company "2". These areas were estimated in good approximation by introducing the values of some characteristic parameters as "length overall", "length waterline", and "draught" in the spread-sheet of a CAD software (Figure 1c); either for the motor-boats or the sailing-boats, the deck house was deliberately not reproduced to make the calculation work easier. Interestingly, these geometric areas correspond to the surfaces of those structural components entirely realized in 
composite material (glass-fibre or carbon-fibre). Thus, the glass-fibre (case-study company "1") or carbon-fibre (case-study company "2") areas of each boatmodel were then multiplied respectively by the number of motor-boats or sailing-boats realised year by year for that model. In this way, it was possible to calculate approximately the total annual values of glass-fibre or carbon-fibre representative areas realised by the considered case-study companies during each year of the overall monitoring period. Consequently, the proposed "WPCpA" coefficient is defined as $\mathrm{t}_{\mathrm{waste}} \mathrm{m}_{\text {boat }}^{-2} \mathrm{y}^{-1}$.

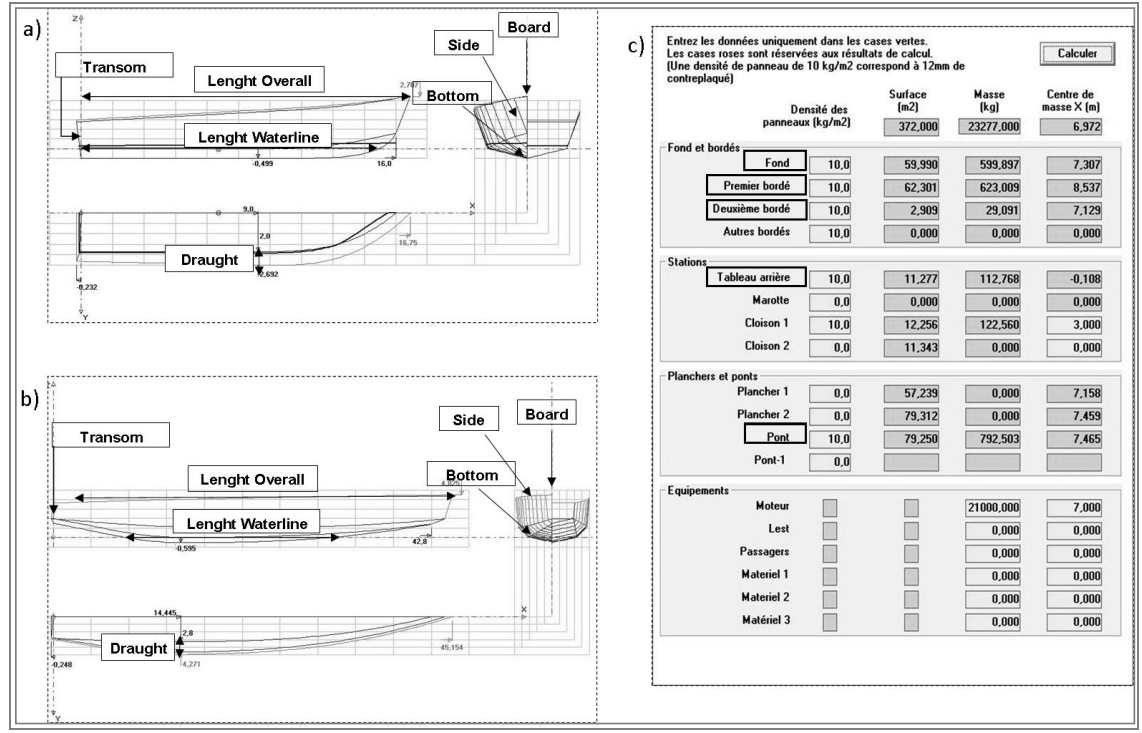

Figure 1: Example of modelling of a motor-boat (a: top left) or a sailing-boat (b: lower left) by means of a CAD software: in the lay-out (c: right), the main elements necessary to the calculation of the representative boat areas are pointed. The CAD software language was French (c: right): thus, the relevant terms "Fond", "Premiere Bordé", "Deuxieme Bordé", "Tableau Arriére", and "Pont" correspond respectively to the terms "Bottom", "Board", "Side", "Transom", and "Deck".

Finally, the further elaboration of the innovative "Waste Production Coefficient per boat-Weight unit (WPCpW)" was based on the displacement value of each boat-model. The displacement is generally defined as the weight of fluid displaced by a floating body. The displacement weight value of each boatmodel was then multiplied by the number of boat units yearly realised for that model, until obtaining the value of total tonnes of boats built per year. Thus, the proposed "WPCpW" coefficient is defined as $\mathrm{t}_{\text {waste }} \mathrm{t}_{\mathrm{boat}}{ }^{-1} \mathrm{y}^{-1}$. 


\subsection{Chemical-physical characterisation of particular composite waste types}

The analysis of the chemical-physical characteristics of a particular waste is fundamental to obtain information for defining reliable options for its recovery. The two representative composite-based residues of the boat building sector are the glass fibre-reinforced plastic and the carbon fibre-reinforced plastic wastes. Consequently, the following representative residue samples were collected the shipyards of the case-study companies involved in the project: a limited stock of glass-fibre residues (Figure 2, left-hand side), and a sample of "pre-preg" (i.e., pre-impregnated) carbon-fibre residue (Figure 2, right-hand side), both containing epoxy resin and in post-hardening phase. For these composite residual types, the following laboratory property determinations were carried out: moisture content, ash content, ultimate analysis, HHV (higher heating value) and LHV (lower heating value). The moisture content was determined by drying at $105^{\circ} \mathrm{C}$. The ash content was estimated by ignition at $600{ }^{\circ} \mathrm{C}$ in a muffle furnace. Each sample was subjected to the ultimate analysis [7] to determine the material heating values. The HHV and the LHV values were calculated as average values of three estimations (on a wet basis) using the Chang, Boie and modified DuLong equations, according to the specific calculation spread-sheet that was developed and included in [8].

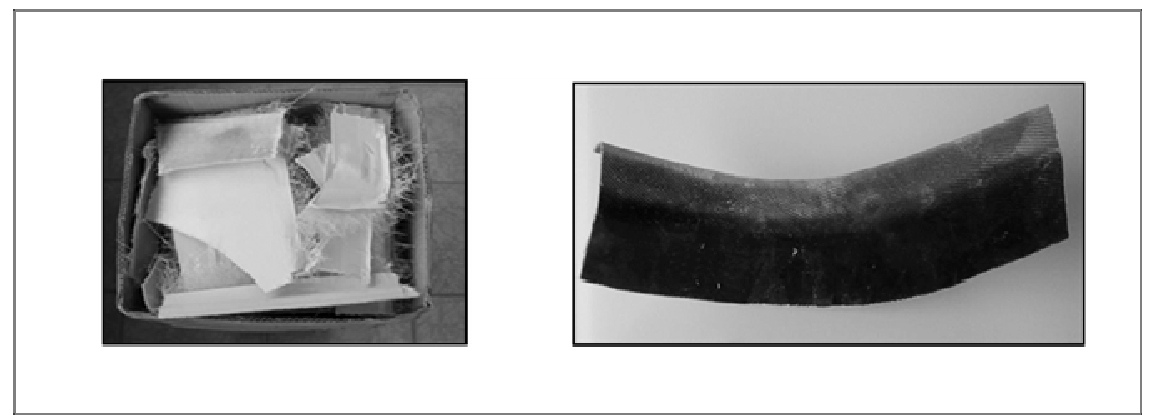

Figure 2: $\quad$ View of the collected stock of representative glass-fibre residues (left-hand side) and of the carbon-fibre residue (right-hand side).

\section{Summary of results and discussion}

\subsection{Territorial distribution of boat-building sites in Marche region}

The data regarding the location of the boat-building companies within the municipal areas of the different tows of Marche Region, were elaborated with the GIS software "uDig" (Release 1.2, M-8 version) to obtain a comprehensive map of the territorial density of the companies related to the last monitoring year (2009). The resulting map of Figure 3 shows a predominant concentration of the boat building district in the upper coastal area of the Province of Pesaro-Urbino, where the Fano sea-town is characterised by no. 42 productive units, while 


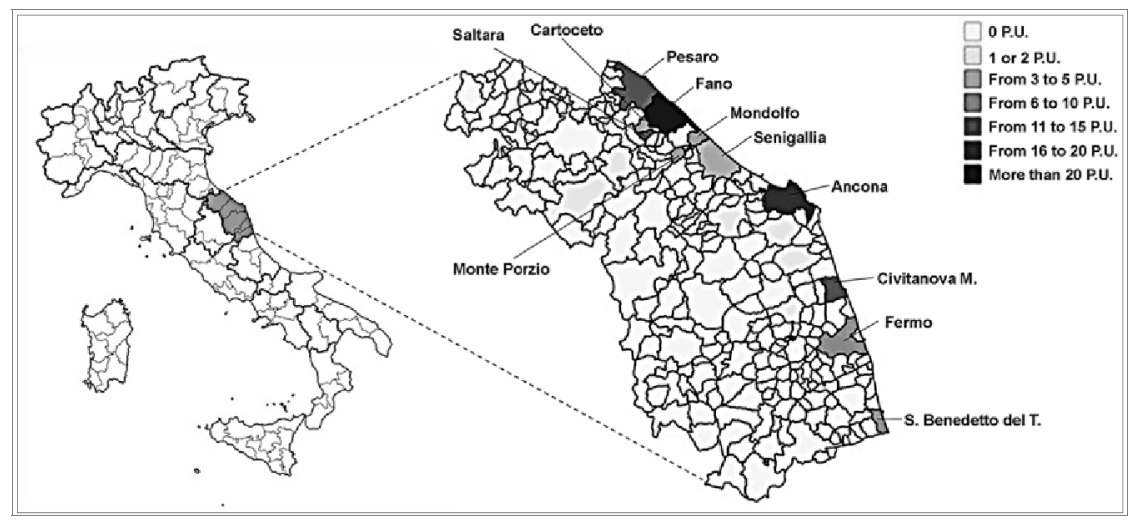

Figure 3: Territorial distribution of the productive units (acronym "P.U.") in the boat building sector of Marche Region (Central Italy, Adriatic Sea side) for the year 2009 .

no. 15 , no. 14, and no. 10 productive units are located in Pesaro, Saltara, and Mondolfo towns, respectively. In the remaining provincial territories of Marche Region, the sea-towns of Ancona, Civitanova Marche, and San Benedetto del Tronto count for no. 18 , no. 13, and no. 9 active productive sites, respectively.

\subsection{Temporal evolutions of the waste production coefficient per employee}

Figure 4 shows the temporal evolutions of the "WPCpE, Waste Production Coefficient per Employee" values for the entire Marche region district and for the three case-study companies, either referring to the total annual waste amounts or to the waste amounts per each two-digit "CER" code (in accordance with the aforementioned European Waste List and its Italian implementation).

The "WPCE" elaboration for the entire Marche regional district (Figure 4a) highlights how the related 2006 annual value (in terms of total wastes) is excessively low, and thus substantially unreliable in contrast with the subsequent 2007 and 2008 annual values. Focusing the attention on these last two years, it appears evident that the highest incidence of annual wastes is comparatively constituted by "waste packaging" (two-digit code "15"), followed by "wastes from organic chemical processes" (two-digit code "07") and "wastes from wood processing and production of panels, furniture, pulp, paper, and cardboard" (twodigit code "03"). This profile is essentially maintained also for the 2009 year, even if the whole waste flux (as reflected by the "WPCpE" value) appears noticeably reduced, probably as the expected effect of the intense economic crisis occurred also in the Italian boat building sector during the last years.

The waste evaluation in terms of "WPCpE" for the case-study company " 1 ", specialized in glass-fibre motorboats building, is shown in Figure 4b. Five twodigit code waste categories were produced by this company with an appreciable increasing of the considered total waste production coefficient from 2006 to 2008, while a moderate decreasing characterises the subsequent 2009 year. The 
most copious waste macro-categories are those identified by the aforementioned two-digit codes " 03 " and " 15 ", followed by the aforementioned two-digit code "07". Perplexity arises above the waste macro-category of "wastes from thermal processes" (two-digit code "10") entirely referable, in this case, to the "101103" six-digit code (i.e., "waste glass-based fibrous materials"): in fact, a total and inexplicable (given the production typology) disappearance of this waste code occurred in 2008 and 2009 years. Partial explanation to this anomaly could be the possible aggregation of this waste typology within the "07" macro-category.

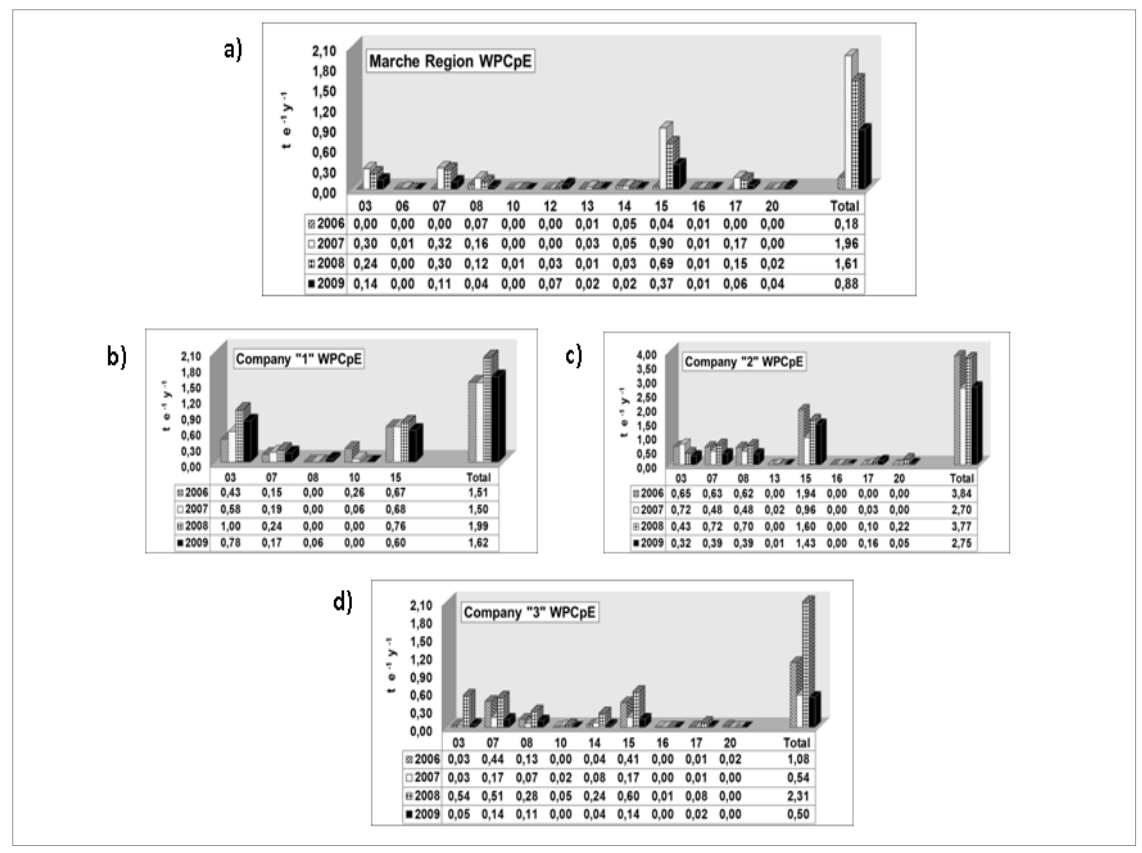

Figure 4: Annual evolutions of "WPCpE, Waste Production Coefficient per Employee" (as $\mathrm{t}_{\text {waste }} \mathrm{e}^{-1} \mathrm{y}^{-1}$ ) diversified per two-digit "CER" waste code and the total waste amount, for : a) Marche regional boat building sector; b) case-study company "1"; c) case-study company " 2 "; and d) case-study company "3".

Figure 4c shows the "WPCpE" annual evolution for the case-study company " 2 " specialised in the building of high quality carbon-fibre sailing-boats. No. 25 waste typologies referable to no. 8 "CER" macro-categories were identified for this company in the four-year period 2006-2009. The waste macro-category " 15 " is the most abundant, followed by waste macro-categories " 03 ", "07", and "08" (properly representing "wastes from manufacture and use of coatings, adhesives, sealants"). In the case of company " 2 ", the absence of a precise six-digit "CER" code for the specific carbon fibre-reinforced plastic waste makes it complex the correct flux identification of this particular waste among the other wastes and in 
whole productive cycle. Referring to the total waste generation, the "WPCpE" annual values of case-study company " 2 " are approximately two-fold the corresponding values of previous case-study company " 1 ". This result would suggest a major specific waste generation in the sailing boat manufacturing with carbon-fibre composite material. Effectively, this hypothesis seems congruent with the building procedure adopted by the case-study company "2", based on male moulds different from each other and thus intended to become waste, given the not mass production dimension of the company. On the contrary, the female moulds characterising the glass-fibre boat manufacturing are cyclically reusable, giving arise to a limited final waste amount.

With final regard to the case-study company " 3 " specialised in the manufacturing of glass-fibre boat components, no. 17 different waste typologies and no. 9 "CER" macro-categories were identified (Figure 4d). A clear peak of the total waste specific coefficient is revealed for the 2008 year. Also in this case, the most relevant "CER" waste macro-category generally consists of the two-digit code " 15 ", followed by "07", "08", and "14" (properly representing "waste organic solvents"). The "CER" waste macro-category "10", entirely referable also in this case to the aforementioned "101103" six-digit code, deserves a particular attention: in 2006 and 2009, the relative amounts are nearly absent. Indeed, the hypothesis of aggregation of this particular waste typology within the "07" CER waste macro-category, as for the previous case-study company " 1 ", could be connected for the case-study company " 3 " with the resulting non-negligible quantities of the specific six-digit code "070299" (generally representing "wastes not otherwise specified").

\subsection{Temporal evolutions of the waste production coefficients per boat-area unit and boat-weight unit}

Figure 5 shows the temporal evolutions of the original "WPCpA, Waste Production Coefficient per boat-Area unit" and "WPCpW, "Waste Production Coefficient per boat-Weight unit" for two case-study companies, either referring to the total annual waste amounts or to the waste amounts per each two-digit "CER" code.

At first referring to the specific waste production coefficient related to the representative boat area, the case-study company " 1 " presents "WPCpA" total annual values almost close during the considered monitoring period (2006-2009) (Figure 5a, left-hand side), while the case-study company "2" shows a certain value increasing during the last two years (Figure 5b, left-hand side). Moreover, the waste flux analysis made through the "WPCpA" approach confirms essentially what highlighted in the previous paragraph, i.e., the predominance of the "CER" waste macro-category " 15 " upon the other waste typologies for the specific boat building industrial sector. This comparative condition is particularly appreciable for the carbon-fibre based sailing-boat building represented by the case-study company " 2 " (Figure 5b, left-hand side).

Considering the alternative waste production coefficient related to the representative boat weight, the resulting annual evolutions of "WPCpW" for the two case-study companies (Figure 5, right-hand side), although with higher 
values, are perfectly specular with the previous "WPCpA" temporal trends, thus suggesting a certain reliability and reproducibility of the use of reference parameters intrinsic to the final product in the waste flux characterisation through unit generation rates.
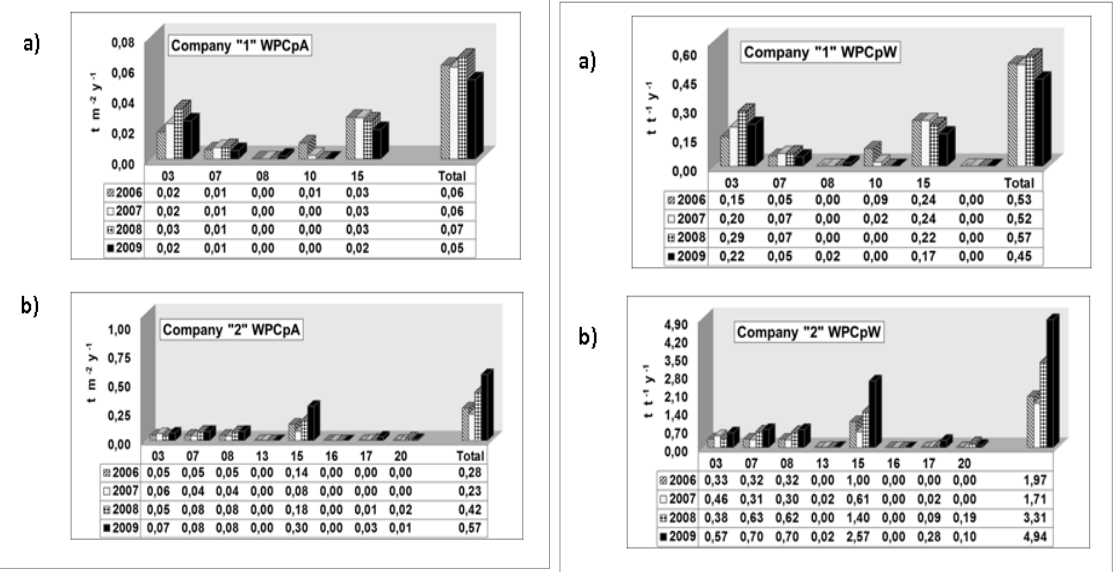

Figure 5: Annual evolutions of "WPCpA, Waste Production Coefficient per boat-Area unit" (as $\mathrm{t}_{\text {waste }} \mathrm{m}^{-2}$ boat $\mathrm{y}^{-1}$ ) (left-hand side: a, case-study company "1"; b, case-study company "2") and "WPCpW, Waste Production Coefficient per boat-Weight unit" (as $t_{\text {waste }} t_{\text {boat }}{ }^{-1} y^{-1}$ ) (right-hand side: a, case-study company "1"; b, case-study company "2").

\subsection{Chemical-physical properties of particular composite wastes}

Experimentally characterised data on the chemical-physical properties of the two representative types of composite waste from the boat building sector are reported in Table 1. At first, the moisture contents of the glass-fibre residue and the carbon-fibre residue resulted particularly low.

Table 1: Experimental chemical-physical properties of two representative composite wastes.

\begin{tabular}{|c|c|c|c|c|c|}
\hline $\begin{array}{c}\text { Material } \\
\text { sample }\end{array}$ & $\begin{array}{c}\text { Moisture } \\
\text { content (\%, } \\
\mathbf{w} / \mathbf{w})\end{array}$ & $\begin{array}{c}\text { Ash } \\
\text { content on } \\
\text { dry basis } \\
(\mathbf{\%}, \mathbf{w} / \mathbf{w})\end{array}$ & $\begin{array}{c}\text { Ash } \\
\text { content on } \\
\text { wet basis } \\
(\%, \mathbf{w} / \mathbf{w})\end{array}$ & $\begin{array}{c}\text { HHV } \\
\left(\mathbf{k c a l ~ k g}^{-1}\right)\end{array}$ & $\begin{array}{c}\mathbf{L H V} \\
\left(\mathbf{k c a l ~ k g}^{-1}\right)\end{array}$ \\
\hline $\begin{array}{c}\text { Glass-fibre } \\
\text { residue }\end{array}$ & 0.60 & 34.61 & 34.40 & $3,545.7$ & $3,380.7$ \\
\hline $\begin{array}{c}\text { Carbon-fibre } \\
\text { residue }\end{array}$ & 0.90 & 30.98 & 30.70 & $4,843.9$ & $4,674.7$ \\
\hline
\end{tabular}


Referring to the ash content, the experimental results of Table 1 shows considerable contents (higher than 30\%) for both the considered composite materials. These values particularly high are reasonably attributable to the whole weight of the inorganic fraction (glass or carbon) of the composite material samples, with the consequential result - given the ash content determination carried out by calcination - of the thermal degradation of the volatile organic fraction (i.e., the thermosetting resin) with the recovery of "clean" inorganic fibres.

The experimental results of the ultimate analysis of the two representative residues (data not extensively reported) highlight a net predominance of the carbon element percentage in both of them, with a resulting value for the carbonfibre residue (i.e., $51.67 \%$, w/w on dry basis) higher than that of the glass-fibre residue (i.e., $39.45 \%$, w/w on dry basis). Oxygen is the secondly most abundant element, with a resulting weight percentage in the glass-fibre waste (i.e., $22.53 \%$, $\mathrm{w} / \mathrm{w}$ on dry basis) almost double than that in the carbon-fibre residue (i.e., $12.81 \%$, w/w on dry basis).

The experimentally determined energy contents of the two representative composite residues (Table 1) are considerable, with both HHV and LHV values resulting higher for the carbon-fibre material as compared with the glass-fibre material. Interestingly, each of the experimental LHVs listed in Table 1 is well above the limit of $5,000 \mathrm{~kJ} \mathrm{~kg}^{-1}$ (i.e., 1,195 $\mathrm{kcal} \mathrm{kg}^{-1}$ ), which is assumed in Reimann and Hämmerli [9] as a relevant condition for a thermally self-sufficient state of waste combustion. Moreover, the experimentally determined values of LHV presented in Table 1 are higher in comparison with the residual municipal solid waste, which is currently characterised by a representative LHV of 10,000$11,000 \mathrm{~kJ} \mathrm{~kg}^{-1}$ (i.e., approximately 2,390-2,630 $\mathrm{kcal} \mathrm{kg}^{-1}$ ) in Italy [10].

\section{Conclusions}

The quantitative and qualitative analysis of specific industrial wastes generated at a given territorial scale, is a preliminary and necessary step for the subsequent individuation of reliable and feasible integrated management options. In this perspective, the paper synthetically presented the results of the parametrical and chemical-physical characterisation concerning the particular industrial wastes generated in the boat building sector of Marche Region (Central Italy, Adriatic Sea side) with reference to the four-year monitoring period 2006-2009. Interestingly, two innovative waste production coefficients were proposed and applied, as properly based on either the boat area unit or the boat weight unit. With regard to the quantitative incidence of the particular waste represented by composite glass-fibre residues, the elaboration carried-out for the case-study companies " 1 " and " 3 " pointed out that the glass-fibre waste amounts are underestimated in all probability, due to an expected inhomogeneity of the resulting digit-code categorisation. Finally, the chemical-physical characterisation of two representative composite wastes from the boat building sector, namely a glass-fibre residue and a carbon-fibre residue, is a preliminary condition for identifying potential options of material and/or energy recovery. 
For instance, the calcination process, normally executed to characterise the ash content, could be representative of a possible way to recover the glass fibres and make them available to recycling processes with potential production of medium-quality glass or cement [11].

\section{Acknowledgements}

The first phase - presented and discussed in the paper - of the aforementioned "GeRiSNaM" project was supported by the Marche Region, under the specific Deliberation "DDS No. 40/S11, 17/06/2009, Distretto del Mare". The Authors would like to mention: Ing. M. Beccaria, Mr. E. Sora, Dr. L. Curina, and Dr. A. Urizio, for providing the informative data on the case-study companies; Dr. M. Boccarossa (ARPA Marche), for providing the waste declaration data related to the entire boat building sector of Marche Region; Dr. S. Scatassa (Camera di Commercio PU), Mrs. A. Ria (INPS PU), Dr. M. Gardini (INPS AN), Dr. A. Taruschio (INPS MC), and Dr. P. Marini (INPS AP), for providing the statistical data on productive sites and workers.

\section{References}

[1] Directive 2008/98/EC on waste and repealing certain Directives, Official Journal of the European Union, L 312/3-30, 22.11.2008.

[2] Legislative Decree No. 152, Environmental Framework Regulation, Annex of the Italian Official Gazette No. 88, April 14, 2006 (in Italian).

[3] Commission of the European Communities, Decision 2000/532/EC establishing a List of Wastes, consolidated version, 2000, available from http://www.eur-lex.europa.eu

[4] Lagerkvist, A., Ecke, H. and Christensen, T.H., Waste characterisation: Approaches and methods, Solid Waste Technology \& Management, Volume 1 (Christensen T.H. Editor), John Wiley \& Sons, Ltd, pp. 63-84, 2010.

[5] Christensen, T.H., Industrial waste, Solid Waste Technology \& Management, Volume 1 (Christensen T.H. Editor), John Wiley \& Sons, Ltd, pp. 100-103, 2010.

[6] Italian Environmental Protection Agency (ANPA), Industrial Wastes: Methodologies for Calculation of Waste Production Coefficients, Report No. 18/02, Rome, Italy, 2002. (in Italian)

[7] Tchobanoglous, G., Theisen, H. and Vigil, S.A., Integrated Solid Waste Management: Engineering Principles and Management Issues, McGrawHill, Inc., New York, USA, 1993.

[8] Niessen, W.R., Combustion and Incineration Processes, Third Edition (revised and expanded), Marcel Dekker, Inc., New York, USA, 2002.

[9] Reimann, D.O. and Hämmerli, H., Verbrennungstechnik für Abfälle in Theorie und Praxis, Schriftenreihe Umweltschutz, Bamberg, Germany, 1995. 
[10] Canziani, R., Waste composition, Handbook of Civil and Environmental Engineering (Riva P.A. and Guadagni A., Eds.), Hoepli Publisher, Milan, Italy, pp. G223-G229, 2011. (in Italian)

[11] Sponberg, E.W., Recycling dead boats, Professional Boat Builder, 60, pp. 82-95, 1999. 